\title{
Target-Dependent Release of a Presynaptic Neuropeptide Regulates the Formation and Maturation of Specific Synapses in Aplysia
}

\author{
Jiang-Yuan Hu, Jonathan Goldman, Fang Wu, and Samuel Schacher \\ Center for Neurobiology and Behavior, Columbia University College of Physicians and Surgeons, New York State Psychiatric Institute, New York, \\ New York 10032
}

\begin{abstract}
The correct wiring of neurons is critical for the normal functioning of the nervous system. Sensory neurons of Aplysia form synapses with specific postsynaptic targets. Interaction with appropriate target cells in culture induces a significant increase in axon growth, the number of sensory neuron varicosities with release sites contacting the target, and regulates the expression and distribution of mRNAs encoding presynaptic proteins such as syntaxin and the sensory neuron-specific neuropeptide sensorin. Synapse stabilization is accompanied by the maintenance of presynaptic varicosities and target-dependent regulation of mRNA distributions. We report here that specific targets induce the release of sensorin from sensory neurons, which then regulates synaptic efficacy, axonal growth associated with synapse formation, the maintenance of synaptic contacts, and the specific distribution of mRNAs. Bath application of an antisensorin antibody during the early phase of synapse formation blocked the expected increase in synaptic strength, the growth and formation of new presynaptic varicosities, and the target-dependent regulation of mRNA distribution. In contrast, bath application of sensorin accelerated the increase in synaptic strength and enhanced the formation of new varicosities and target-dependent regulation of mRNA distribution in sensory neurons. As synapses stabilize, sensorin secretion declines but is required for the maintenance of synaptic efficacy, presynaptic varicosities, and mRNA distributions. These results suggest that a retrograde target signal regulates the secretion and actions of a presynaptic neuropeptide critical for the formation and maintenance of specific synapses.
\end{abstract}

Key words: retrograde signal; sensorin; autocrine response; synaptic growth; syntaxin; mRNA distribution; cell culture

\section{Introduction}

The formation of specific synapses is critical for the normal functioning of the nervous system. Cell surface or secretory molecules that bind specific receptors contribute to this specificity. These factors must regulate axon trajectory (for review, see TessierLavigne and Goodman, 1996; Huber et al., 2003), growth, branching and development of presynaptic terminals and postsynaptic sites during synapse formation and stabilization (for review, see Benson et al., 2001; Scheiffele, 2003), and establishment and long-term maintenance of appropriate synaptic contacts (for review, see Katz and Shatz, 1996; Davis and Bezprozvanny, 2001).

Many Aplysia neurons are identified functionally because of their specific connections. In culture, Aplysia neurons (sensory neurons or interneuron L10) form specific synapses when con-

Received June 14, 2004; revised Sept. 21, 2004; accepted Sept. 23, 2004.

This work was supported by National Institutes of Health Grants MH 60387 and NS 42159. Animals were provided by the National Center for Research Resources for Aplysia at the University of Florida (Miami, FL), which is supported by National Institutes of Health Grant RR-10294. We thank Drs. Jinming Liu, James H. Schwartz, and Denong Wang for their technical advice, helpful discussions, and comments on previous drafts of this manuscript.

Correspondence should be addressed to Samuel Schacher, Center for Neurobiology and Behavior, Columbia University College of Physicians and Surgeons, New York State Psychiatric Institute, 1051 Riverside Drive, New York, NY 10032.E-mail: sms2@columbia.edu.

DOI:10.1523/JNEUROSCI.3329-04.2004

Copyright $\odot 2004$ Society for Neuroscience $\quad$ 0270-6474/04/249933-11\$15.00/0 fronted with either individual targets or multiple targets simultaneously (Camardo et al., 1983; Hawver and Schacher, 1993; Schacher et al., 1999). Many important cellular changes in sensory neurons accompany contact and synapse formation with motor neuron L7 compared with contact with motor neuron L11, which fails to form synapses with sensory neurons: an increase in presynaptic axon growth and varicosity formation contacting the target (Glanzman et al., 1989; Schacher and Montarolo, 1991), the full development of transmitter release sites in varicosities contacting L7 (Glanzman et al., 1989; Hatada et al., 1999, Kim et al., 2003), and differences in the expression and distribution of specific mRNAs that encode proteins critical for synaptic function (Schacher et al., 1999; Hu et al., 2002, 2003). The distribution of syntaxin mRNA in the cell body of sensory neurons is regulated by target interaction both during the early phase of synapse formation and when synapses are stabilized $\mathrm{CHu}$ et al., 2003). Target interaction and synapse formation also regulate the expression and distribution of sensorin mRNA and protein in sensory neuron cell bodies and varicosities and transport of sensorin mRNA to distal sites (Santarelli et al., 1996; Schacher et al., 1999; Hu et al., 2002). Sensorin, the sensory neuron-specfic neuropeptide, produces hyperpolarizations in some unidentified postsynaptic targets that matches responses produced by electrical activity in sensory neurons (Brunet et al., 1991). Sensorin also appears to have a neurotrophin-like function in producing long- 
term synaptic plasticity at mature sensory neuron synapses $(\mathrm{Hu}$ et al., 2004). Secretion of sensorin from sensory neurons is regulated by repeated applications of 5-HT in which sensorin then binds autoreceptors to activate and translocate MAPK (mitogenactivated protein kinase) into sensory neuron nuclei that is required for long-term synaptic facilitation and the accompanying growth and formation of new sensory neuron varicosities. These results raised the possibility that sensorin secretion and its autocrine action may also contribute to the initial formation of sensory neuron synapses.

We report here that the secretion of sensorin and its responses are regulated by contact with L7 and mediate target-dependent actions associated with specific synapse formation: axon growth and varicosity formation and regulation of mRNA distribution. The maintenance of stable sensory neuron synapses also requires the constitutive action of sensorin. Thus, the regulated secretion of a neuropeptide and its autocrine actions play an instructive role in the formation and maintenance of specific synapses.

\section{Materials and Methods}

Cell culture and electrophysiology. Sensory neurons were isolated from pleural ganglia dissected from adult animals ( $80-100 \mathrm{gm})$; motor cell L7 and L11 were isolated from juvenile (1-3 gm) abdominal ganglia and maintained in culture medium $(2 \mathrm{ml})$ from 1 to $7 \mathrm{~d}$ as described previously (Rayport and Schacher, 1986; Schacher et al., 1999). Culture medium was a 1:1 (by volume) mixture of Aplysia hemolymph and L15 medium with added salts to match ionic composition of seawater (Rayport and Schacher, 1986). Cells were plated on a poly-L-lysine-coated glass coverslip that was glued to the bottom of plastic culture dishes with a $12 \mathrm{~mm}$ circular hole (MatTek, Ashland, MA). The volume of the culture well was $250 \mu \mathrm{l}$. Individual sensory neurons were plated in the same culture dishes as cocultures at very low density to prevent cells from contacting each other. Cocultures consisted of one sensory neuron with one L7 or one L11 (SN-L7 or SN-L11). Some dishes contained both an SN-L7 and an SN-L11 coculture.

Standard electrophysiological techniques were used to record the amplitude of the EPSP evoked in L7 with the stimulation of each sensory neuron (Schacher and Montarolo, 1991; Schacher et al., 1999). The L7 was impaled with a microelectrode containing $2.0 \mathrm{M} \mathrm{K}$-acetate, $0.5 \mathrm{M} \mathrm{KCl}$, and $10 \mathrm{~mm} \mathrm{K-HEPES,} \mathrm{pH} \mathrm{7.4,} \mathrm{and} \mathrm{held} \mathrm{at}-85 \mathrm{mV}$. Each sensory neuron was stimulated with a brief $(0.3-0.5 \mathrm{msec})$ depolarizing pulse to evoke an action potential using an extracellular electrode placed near the cell body of the sensory neuron.

Imaging sensory neuron growth and varicosities. The fluorescent dye 5(6)-carboxy-fluorescein (6\% in $0.44 \mathrm{M} \mathrm{KOH}, \mathrm{pH} 7.0$; Molecular Probes, Eugene, OR) was injected into sensory neurons with 0.3-0.5 nA hyperpolarizing current pulses $(500 \mathrm{msec}$ at $1 \mathrm{~Hz}$ ) for 5-6 min (Glanzman et al., 1989; Schacher and Montarolo, 1991). Nomarski and fluorescent images of the same view areas $400-500 \mu \mathrm{m}$ along the major axons of L7 were taken to map out the location of sensory neuron varicosities and neurites at each time point. Varicosities were defined as swellings along the sensory neuron neurites with diameters $\geq 1.5 \mu \mathrm{m}$. Such structures contacting the major processes of L7 contain active zones (Glanzman et al., 1989; Hatada et al., 1999) with vesicular pools that recycle with activity (Kim et al., 2003). Images were taken with a Nikon (Tokyo, Japan) Diaphot microscope attached to an SIT (Dage 68; Dage-MTI, MI City, IN) video camera, processed by a Dell computer (Dell Computer Company, Round Rock, TX) with the MCID 7.0 software package from Imaging Research (St. Catharines, Ontario, Canada). In sensory neuronalone cultures, Nomarski images were taken on days 1 and 2 .

Sensorin peptide, antibody, and immunocytochemistry. Cultures were incubated with sensorin peptide (SEN) (sensorin B, $100 \mathrm{ng} / \mathrm{ml}$ ) or antisensorin antibody (SEN Ab) (400 ng/ml) or control Ab (Cont Ab) (400 $\mathrm{ng} / \mathrm{ml}$, protein A-purified preimmune serum) for 1-2 d. We used sensorin B (Brunet et al., 1991) (TRSKNNVPRRFPRARYRVGYMF- $\mathrm{NH}_{2}$ ) instead of sensorin A because the shorter sensorin A peptide is the $\mathrm{C}$-terminal end of the longer sensorin $\mathrm{B}$ peptide. Anti-sensorin $\mathrm{Ab}$ was a rabbit polyclonal antibody (Prosci, Poway, CA) generated against the antigen sensorin B peptide linked to KLH (keyhole limpet hemocyanin) and was affinity purified using the antigen itself (Liu et al., 2003).

To test specificities of antibody or peptide actions, sensorin and its antibody at approximately equimolar concentrations (5 ng Ab per $1 \mathrm{ng}$ peptide) were preincubated for $30 \mathrm{~min}$ before their application to live cultures or fixed cultures for immunostaining (Liu et al., 2003; Hu et al., 2004). Application of preincubated peptide-Ab complex failed to affect properties of the developing synapses (day 1 to day 2 changes in EPSP amplitude or growth). For immunostaining, fixed cultures were exposed to rabbit polyclonal sensorin antibody (1:1000) diluted in $2 \%$ normal goat serum in $0.01 \mathrm{M} \mathrm{PBS}$ with $0.3 \%$ Triton X-100 at $4^{\circ} \mathrm{C}$ for $24 \mathrm{hr}$. The cultures were washed in $0.01 \mathrm{~m}$ PBS and incubated in FITC-conjugated goat anti-rabbit IgG (1:200; Sigma, St. Louis, MO) at $4^{\circ} \mathrm{C}$ for $4 \mathrm{hr}$. After washing in $0.01 \mathrm{~m}$ PBS, cultures were imaged with a filter set for detecting fluorescein signal. Other control experiments were performed to test the specificity of the primary antibody, including the substitution of normal rabbit serum for the primary antibody and omission of the primary antibody. All controls showed little immunocytochemical reaction.

Western blots. Culture containing five to six L7s or L11s with $\sim 25-30$ sensory neurons were plated in separate cultures in the same culture medium for $5 \mathrm{~d}$. Culture medium (100 $\mu \mathrm{l}$ of hemolymph/L15) was collected near the cells (from the total volume of $\sim 250 \mu$ in the central well of the culture dish) from each culture on days 1 and 5 for testing the secretion of sensorin by immunoblot. Samples of culture medium $(20 \mu \mathrm{l}$ containing on average $12 \mu \mathrm{g}$ of total protein) from each culture were separated on SDS-PAGE (15\% gels), transferred to nitrocellulose filters, processed as described by Liu and Schwartz (2003). Each lane contained $20 \mu \mathrm{l}$ of sample plus $10 \mu \mathrm{l}$ of sample buffer. The membranes were exposed for $2 \mathrm{hr}$ at room temperature to the anti-sensorin $\mathrm{Ab}$ (1:4000) labeled with biotin using the E-Z Link kit (Pierce, Rockford, IL). After washout, the blots were treated with strepavidin-peroxidase (1:200; Sigma) for $1 \mathrm{hr}$ at room temperature. Immune complexes were visualized after 30-60 sec treatment with ECL Western blot detection reagents (Amersham Biosciences, Piscataway, NJ). Because sensorin was linked to $\mathrm{KLH}$ in the generation of the polyclonal antibody, the antibody crossreacts with other proteins in Aplysia hemolymph. A $75 \mathrm{kDa}$ protein in hemolymph is stained in each lane with comparable intensity. This band serves as an internal control for lane loading. The $75 \mathrm{kDa}$ protein does not appear to be critical, because cultures exposed to Ab preincubated with sensorin expressed the normal increase in synaptic efficacy. When dissolved in L15 alone, a single band was detected at the low molecular weight. We detected sensorin at concentrations as low as $2 \mathrm{ng} / 20 \mu \mathrm{l}$, and bands stained at greater intensity with increasing concentrations of peptide.

In situ hybridization. Antisense oligonucleotide probes were designed for specific coding portions of the target sequences used successfully in reverse transcription-PCR analyses of the mRNAs (Schacher et al., 1999), synthesized (Genset, La Jolla, CA), lyophilized, and redissolved in sterile distilled water. The specific antisense oligonucleotide probe sequences were for syntaxin, sensory neuron-specific neuropeptide sensorin, and actin (for probe sequences, see $\mathrm{Hu}$ et al., 2002, 2003). Their sense probes were also designed for use as nonspecific controls. These probes were labeled at the $3^{\prime}$ end with biotin-ddUTP according to the instructions of the manufacturer (Boehringer Mannheim, Indianapolis, IN).

In situ hybridization was performed as described previously (Hu et al., $2002,2003)$. Briefly, fixed cultures were hybridized overnight at $42^{\circ} \mathrm{C}$ in hybridization buffer ( $50 \%$ deionized formamide, $5 \times$ SSC, $0.02 \%$ SDS, and $2 \%$ blocking reagent) containing $1.5 \mu \mathrm{g} / \mathrm{ml}$ of the biotin-labeled oligonucleotide probes. Unbound probe was washed out. Cultures were then incubated in streptavidin-FITC (1:200; Invitrogen, Gaithersburg, $\mathrm{MD})$ for $4 \mathrm{hr}$ at $4^{\circ} \mathrm{C}$. After unbound antibody was washed out, and the hybridization signals were visualized directly with fluorescent microscopy, imaged with a Nikon, and processed by a Dell computer with the MCID 7.0 software package from Imaging Research. The specificity of biotin-labeled antisense oligonucleotide probe was examined by hybridizing with labeled sense probe or excess unlabeled probe or by omitting probe in hybridization solution as well as RNase pretreatment. All con- 

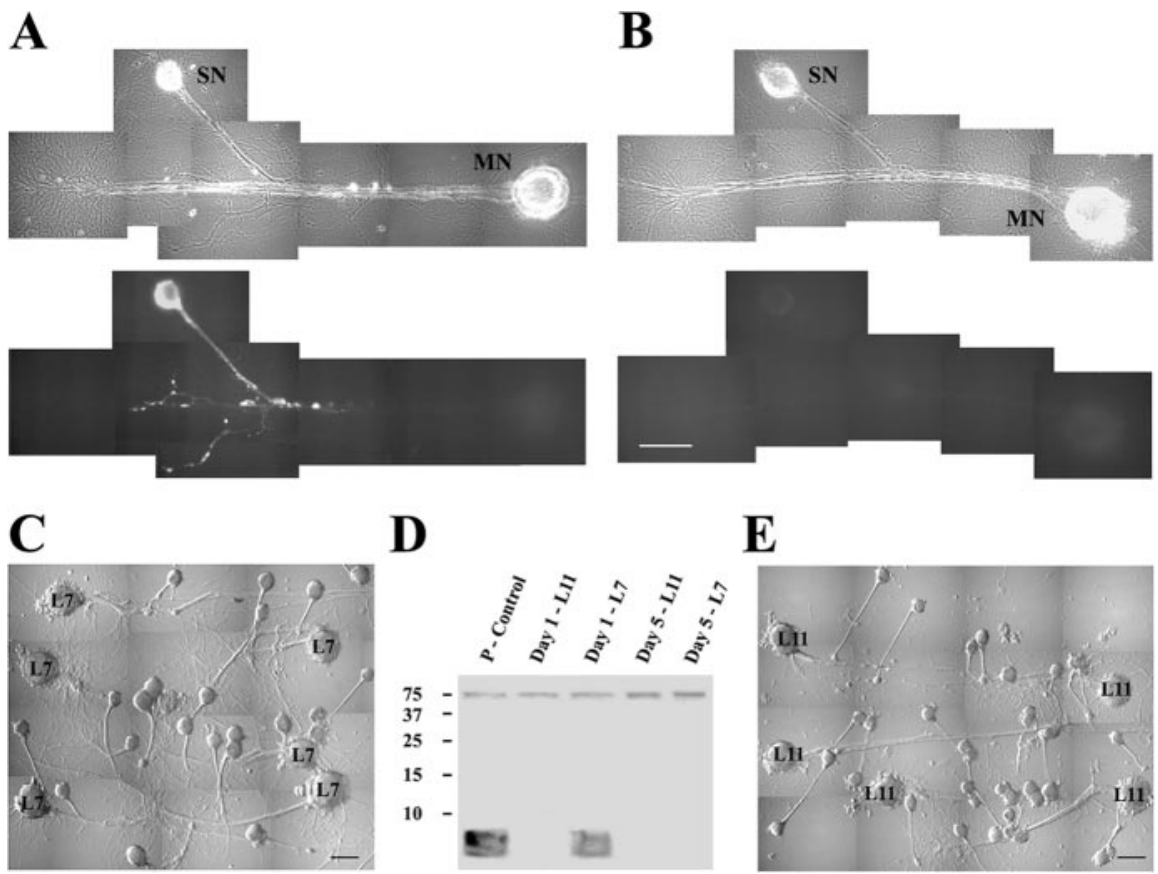

Figure 1. Sensorin is restricted to sensory neurons and is released when sensory neurons contact $L 7$. A, Phase-contrast (top) and epifluorescent (bottom) photomicrographs of an SN-L7 culture $36 \mathrm{hr}$ after plating. Sensorin immunoreactivity is restricted to cell body, axon, regenerated neurites, and varicosities of the sensory neuron. Only weak background staining is detected in the cell body, axons, and neurites of L7. MN, Motor neuron. B, Phase contrast (top) and epifluorescent (bottom) photomicrographs of another SN-L7 culture $36 \mathrm{hr}$ after plating. The primary Ab (anti-sensorin) was preincubated with sensorin for 30 min before its application to the culture. Only background staining is detected. Scale bars, $100 \mu \mathrm{m}$. $C-E$, Sensorin is secreted when sensory neurons contact L7 ( $C$ ) but not L11 $(E)$. Mass cultures containing $L 7$ or $L 11$ with sensory neurons ( $C, 6 \mathrm{~L} 7 \mathrm{~s}$ and 25 sensory neurons; $E, 5 \mathrm{~L} 11 \mathrm{~s}$ and 30 sensory neurons) were imaged $1 \mathrm{~d}$ after plating. A sample of medium was collected with a pipette placed near the cells on days 1 and 5 in culture and analyzed on Western blots (D). Positive control (P-Control) was $50 \mathrm{ng}$ of sensorin dissolved in culture medium. A band migrating at the same location as the peptide was detected in each of the SN-L7 mass cultures on day 1 $(n=4)$, whereas little if any peptide $(<2 \mathrm{ng} / 20 \mu \mathrm{l}$ ) was detected in the SN-L11 mass cultures on day $1(n=4)$. By day 5 , little sensorin peptide was detected in the medium. Anti-sensorin Ab recognized a hemolymph protein above $75 \mathrm{kDa}$ at similar concentrations across all lanes.

trols were negative. Cells were hybridized under the same conditions to reduce variability.

For examining the distribution of the mRNAs in the cell bodies, pixel intensities (normalized arbitrary units) were averaged for six separate areas $\left(25 \mu \mathrm{m}^{2}\right)$ in the peripheral cytoplasm of each sensory neuron cell body. The sites were positioned at clock positions equivalent to 12, 2, 4, 6, 8 , and 10 o'clock (see Figs. 6, 7, positions 1-6). The emergence of the main axon from the sensory neuron cell body was centered at the 6 o'clock (position 4), and signal intensity at the opposiste site (12 o'clock or position 1) was normalized as $100 \%$. The intensities at the other five locations were then compared with and normalized to the signal intensity at the 12 o'clock position. Values for overall expression for the mRNAs in sensory neuron cell bodies were determined by averaging the pixel intensity values for the six areas used to determine distribution.

Quantification and data analysis. All data are expressed as mean \pm SEM produced by the indicated treatments. The change in the net number of varicosities was determined by counting the number of varicosities contacting the major processes of L7 after treatments and dividing that by the number of varicosities contacting the same region of L7 before treatment for each culture. ANOVA and Scheffe $F$ test were used to gauge significant differences between the treatments.

\section{Results}

\section{Target-dependent release of sensorin}

During the early phases of synapse formation, neurites tipped by growth cones emerge from the stump of the sensory neuron axon and extend along the major processes of L7, forming varicosities with transmitter release sites (Hatada et al., 1999). Varicosities on neurites of sensory neurons growing alone, growing in the presence L7 but not contacting L7, or growing and contacting L11 do not have active zones (Glanzman et al., 1989, 1990; Hatada et al., 1999). Most of the new sensory neuron varicosities contacting the major axons of L7 contain sensorin immunoreactivity (Santarelli et al., 1996) (Fig. 1). Cultures fixed and processed for the immunolocalization of sensorin $24 \mathrm{hr}$ (data not shown) or $36 \mathrm{hr}$ (Fig. $1 A)$ after plating reveal significant staining in the cell body, axon, and varicosities of the sensory neurons. In contrast, the cell body, axons, and regenerated neurites of L7 fail to stain. Staining in all compartments of the sensory neuron was blocked if the anti-sensorin $\mathrm{Ab}$ was first preincubated with sensorin (Fig. 1B). Sensory neurons cocultured with L11 formed fewer varicosities on the axons of L11 (Glanzman et al., 1989) and expressed sensorin immunoreactivity that was less than one-half the intensity detected in neurites and varicosities of sensory neurons contacting L7 in the same culture dishes ( $n=3$ culture dishes; data not shown). Sensory neurons express sensorin and transport the peptide to distal varicosities during the early stages of synapse formation with L7. The potential release of sensorin from these newly formed varicosities may contribute to synapse formation.

Sensorin is released when sensory neurons interact with L7 but not with L11. Mass cultures consisting of five to six motor neurons (L7 or L11) were plated with 25-30 sensory neurons and maintained in the same culture medium (Fig. 1C,E), and medium samples were collected near the cells on days 1 and 5 after plating $(n=4$ cultures each). On Western blots (Fig. 1D), a large band was detected in the medium taken from each of the day 1 SN-L7 cultures (staining intensities equivalent to concentrations of sensorin from 10 to $50 \mathrm{ng}$ per $20 \mu \mathrm{l}$ sample) that migrated to the same location as exogenous sensorin peptide. Sensorin levels in the bath were significantly lower $(<2 \mathrm{ng} / 20 \mu \mathrm{l})$ in the same cultures on day 5 after plating. Low levels secreted into the bath were observed, although sensorin expression is high in sensory neuron varicosities contacting L7 on day 5 ( $\mathrm{Hu}$ et al., 2004). No such band was detected in the medium taken from any of the day 1 or day $5 \mathrm{SN}-\mathrm{L} 11$ cultures $(<2 \mathrm{ng} / 20 \mu \mathrm{l})$. Thus, a retrograde signal from L7, but not L11, induces secretion of sensorin during the early stages of synapse formation, and this secretion is reduced as synapses mature.

\section{Sensorin release is required for presynaptic growth associated with synapse formation}

Bath application of sensorin or the anti-sensorin Ab between days 1 and 3 regulates the change in synaptic efficacy during the early phase of synapse formation between sensory neurons and L7 (Fig. 2). During the first $4 \mathrm{~d}$ in culture, the amplitude of the EPSPs evoked in L7 increase as sensory neurons extend neurites and form more varicosities with L7 (Bank and Schacher, 1992; 
A

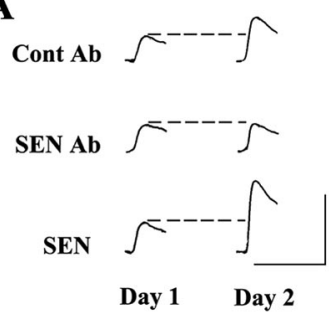

C
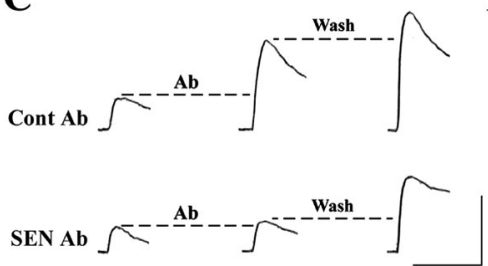

Day 1
B

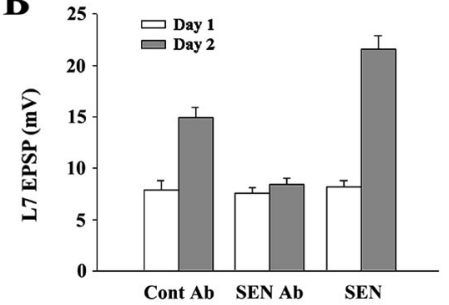

D

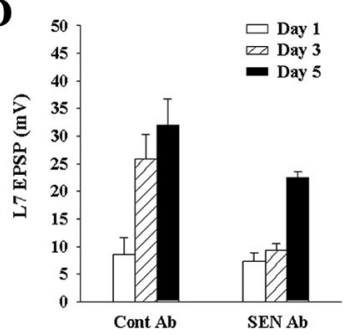

Figure 2. Sensorin regulates changes in synaptic efficacy. $A$, EPSPs were recorded before (day 1) and after (day 2) treatments. Calibration: $20 \mathrm{mV}, 50 \mathrm{msec}$. B, Summary of the changes in EPSP amplitude produced with treatments. The height of each bar is the mean \pm SEM for EPSP amplitudes (in millivolts) recorded before (day 1 ) and after (day 2) treatment. ANOVA indicated a significant effect of treatment over time ( $\mathrm{df}=2,27 ; F=110.6 ; p<0.001)$. Individual comparisons indicated that SEN Ab blocked the increase in EPSP amplitude compared with Cont $\mathrm{Ab}(F=14.368 ; p<0.01)$, whereas SEN enhanced the increase in EPSP amplitude compared with Cont $\mathrm{Ab}(F=16.166 ; p<0.01)$. C, The blockade of the increase in EPSP amplitude during the early phase of synapse formation by SEN Ab is reversible. EPSPs were recorded before (day 1 ) and after (day 3 ) treatments and after washout of the treatments (day 5). EPSPs recorded in L7 after treatment with SEN typically were action potentials (see Results; data not shown). Calibration: $20 \mathrm{mV}, 50 \mathrm{msec}$. D, Summary of the changes in EPSP amplitude produced with treatments. The height of each bar is the mean \pm SEM for EPSP amplitudes (in millivolts) recorded before treatment (day 1 ), after treatment (day 3 ), and after treatment washout (day 5). ANOVA indicated an overall effect of treatment ( $\mathrm{df}=2,19 ; \mathrm{F}=12.349 ; p<0.001$ ). Individual comparisons indicated that SEN Ab blocked the increase in EPSP on day 3 ( $F=$ 51.045; $p<0.01$ ) but not after washout on day 5 .

Zhu et al., 1994; Hatada et al., 1999; Schacher and Wu, 2002). This increase is blocked reversibly by bath applications of antisensorin $\mathrm{Ab}$ (Fig. 2). After recording the synaptic potentials (day 1) cultures were exposed to medium containing $100 \mathrm{ng} / \mathrm{ml} \mathrm{SEN}$ $(n=10), 400 \mathrm{ng} / \mathrm{ml} \mathrm{SEN} \mathrm{Ab}(n=10)$, or $400 \mathrm{ng} / \mathrm{ml} \mathrm{Cont} \mathrm{Ab}(n=$ 10). When synaptic potentials were reexamined $24 \mathrm{hr}$ later (day 2 ), we found that bath-applied anti-sensorin Ab reduced significantly the increase in EPSP amplitude that normally occurs in control cultures: from $7.6 \pm 0.5$ to $8.4 \pm 0.6 \mathrm{mV}$ compared with an increase in EPSP amplitude from $7.9 \pm 0.9$ to $14.9 \pm 1.0 \mathrm{mV}$ when cultures were exposed to Cont $\mathrm{Ab}$. In contrast, sensorin enhanced the increase in EPSP amplitude: from $8.2 \pm 0.6$ to $21.6 \pm 1.4 \mathrm{mV}$ (Fig. $2 A, B$ ). Thus, the sensorin released from sensory neurons during the early phase of synapse formation (Fig. $1 D$ ) contributes directly to the increase in synaptic efficacy. Blocking the actions of sensorin with exogenous Ab prevents the binding of sensorin with receptors that are expressed on the sensory neurons (Hu et al., 2004).

The actions of anti-sensorin $\mathrm{Ab}$ on the change in synaptic efficacy is reversible (Fig. 2C,D) and is correlated with a significant reduction in the growth of sensory neurites and formation of new sensory neuron varicosities that contact the major processes of L7 (Fig. 3). After recording EPSP amplitudes on day 1, cultures were separated into two groups, with each group divided into three treatment groups. One group received the respective treatments, and synaptic strengths were reexamined on days 3 and 5 (Fig. $2 C, D$ ). For the other group, EPSP amplitudes were moni-

tored on days 1 and 3, and sensory neurons were injected with fluorescent dye carboxy-fluorescein (Glanzman et al., 1989) to image sensory neurites interacting with the major axons of L7 before treatments on day 1 and at the end of treatments on day 3 (Fig. 3).

The increase in EPSP amplitudes on day 3 was significantly reduced when cultures were exposed to SEN Ab $(n=11)$ : from $7.8 \pm 1.1$ to $9.7 \pm 1.0 \mathrm{mV}$. When the antibody was washed out, EPSP amplitudes increased significantly by day 5: $23.5 \pm 1.0 \mathrm{mV}$ $(n=5)$ (Fig. $2 C, D)$. As expected, treatment with Cont Ab $(n=$ 11) did not interfere with the expected increase in EPSP amplitude between days 1 and 3: from $8.6 \pm 3.3$ to $25.8 \pm 4.5 \mathrm{mV}$. After the washout, the EPSP amplitude increased modestly to $31.5 \pm$ $4.4 \mathrm{mV}$ on day $5(n=5)$ (Fig. $2 C, D)$. EPSP amplitudes for cultures treated with sensorin over $2 \mathrm{~d}$ were difficult to measure accurately because an action potential in the sensory neuron evoked an action potential in L7 in nearly all cells (7 of 11 cultures; data not shown). Action potentials were evoked, although the L7s were hyperpolarized $\sim 55 \mathrm{mV}$ below threshold for firing an action potential (see Materials and Methods). EPSP amplitudes remained strong (action potentials in three of five cultures) after washout (data not shown). The results indicate that the blocking actions of the antibody are reversible. They suggest that sensorin released after day 3 can bind receptors to enhance synaptic efficacy. The enhancement of the EPSP produced by bath application of sensorin during the early phases of synapse formation persists over the next $48 \mathrm{hr}$. Thus, early exposure to additional sensorin can have long-lasting consequences on the strength of the developing and mature connections.

Sensorin release promotes the growth of new sensory neuron branches with new varicosities contacting the major processes of L7 (Fig. 3). In the presence of the Cont $\mathrm{Ab}(n=6)$, the increase in EPSP amplitude between days 1 and 3 was accompanied by a $31.2 \pm 1.2 \%$ (or $7.0 \pm 0.8$ varicosities) net increase in the number of new varicosities (Fig. $3 B$ ), which were formed primarily by new neurites emerging from the original sensory neuron axon or along extensions of preexisting neurites ( $5.7 \pm 0.4$ neurites) (Fig. $3 C$, Cont $\mathrm{Ab}$ ). In contrast, few new varicosities formed along the major processes of L7, $3.9 \pm 2.7 \%$ (or $0.7 \pm 0.6$ varicosities), when cultures were exposed to SEN Ab $(n=6)$. This reduction in new varicosity formation was correlated with a significant reduction in the growth of new neurites and extensions of preexisting neurites ( $1.0 \pm 0.3$ neurites) (Fig. $3 C$, SEN Ab). Reduced growth and formation of new sensory neuron varicosities were also detected on day 2, after treatment for $24 \mathrm{hr}$ with anti-sensorin $\mathrm{Ab}$ compared with controls (data not shown). In contrast, treatment with SEN $(n=6)$ resulted in a significant enhancement in the number of new sensory neuron varicosities, $45.5 \pm 3.4 \%$ (or $10.3 \pm 1.0$ varicosities), formed by a significant increase in the growth of new neurites and extensions of preexisting neurites (9.8 \pm 0.6 neurites) (Fig. 3C, SEN). Thus, the secretion of sensorin contributes directly to the growth of sensory neurites, the formation of new varicosities contacting L7, and the increase in synaptic efficacy during the early phases of synapse formation.

Sensorin affects synaptic growth but not extension of axons along the substrate deposited on the dish surface (Fig. 4). We examined the effects of anti-sensorin $\mathrm{Ab}$ ( $n=7$ sensory neurons) and sensorin ( $n=7$ cells) on axon extension by sensory neurons plated alone in the same culture dishes as the SN-L7 cells. Compared with incubations with the Cont $\mathrm{Ab}(n=7$ cells), both anti-sensorin $\mathrm{Ab}$ and sensorin applied to cells after $1 \mathrm{~d}$ in culture failed to alter the rate of neurite extension: $115.7 \pm 4.9 \mu \mathrm{m} /$ branch for cells treated with Cont Ab compared with $113.3 \pm 5.0$ 
A

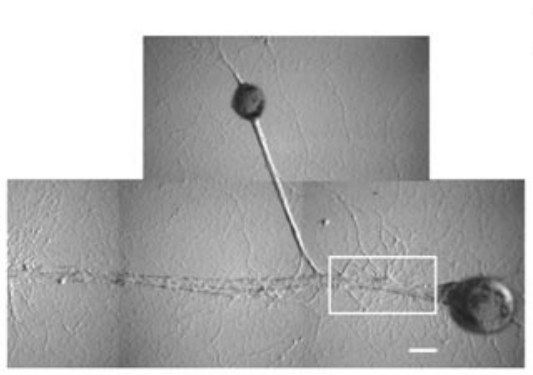

C
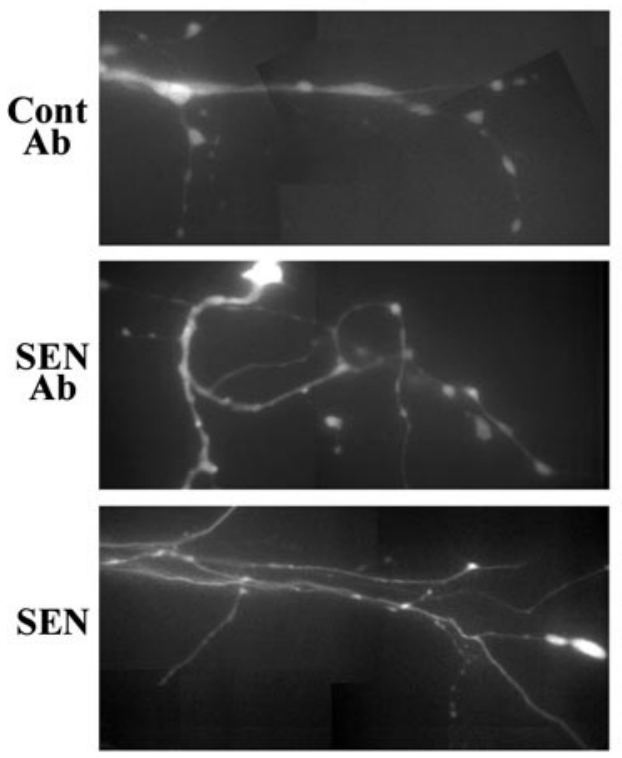

B

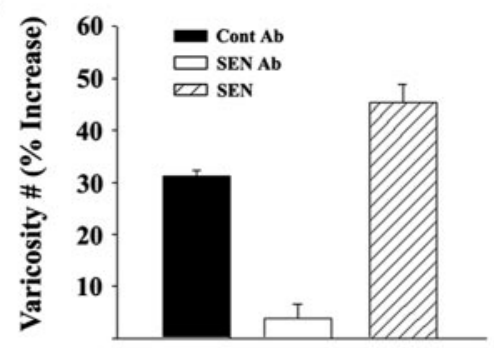

Day 3
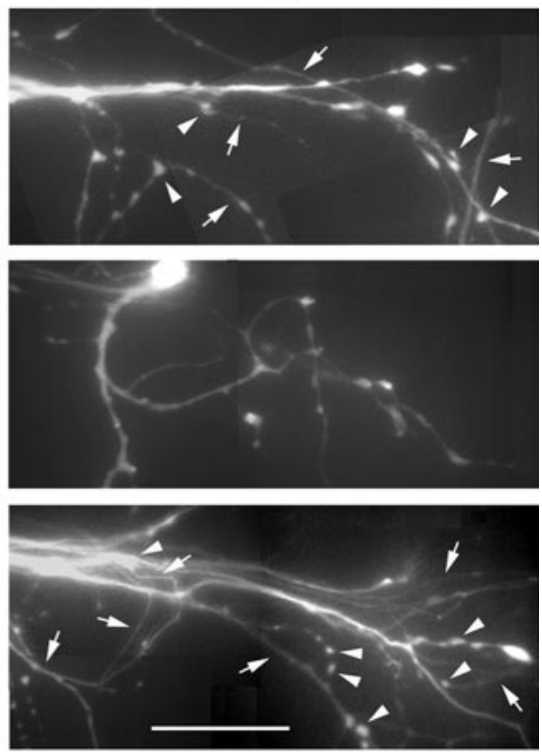

Figure 3. Sensorin regulates growth of new neurites and the formation of new varicosities by sensory neurons contacting L7. $A$, Nomarski contrast photomicrograph of SN-L7 culture on day 1 before treatment with SEN. Inset indicates portion of the major axons of $\mathrm{L} 7$ contacted by a part of the sensory neuron arbor viewed in C (SEN). Scale bar, $50 \mu \mathrm{m}$. B, Summary of the net changes in the number of varicosities formed by sensory neurons contacting $L 7$ after treatments. The height of each bar in the mean $\pm S E M$ for the change (percentage) in varicosities. ANOVA indicated a significant effect of treatment ( $\mathrm{df}=2,15 ; F=65.293 ; p<0.001)$. Before treatment, the average number of varicosities per cell for each treatment group was not significantly different $(p>0.7)$. Individual comparisons indicated that SEN Ab reduced the formation of new varicosities compared with Cont Ab ( $F=27.165 ; p<$ 0.01 ), whereas SEN enhanced the formation new varicosities compared with Cont $\mathrm{Ab}(F=7.516 ; p<0.01)$. ANOVA also indicated a significant effect of treatment on neuritic growth ( $\mathrm{df}=2,15 ; F=87.402 ; p<0.001)$. Individual comparisons indicated that SEN Ab reduced growth compared with Cont $A b(F=22.919 ; p<0.01)$, whereas SEN enhanced growth compared with Cont $A b$ $(F=17.978 ; p<0.01)$. C, Growth of new branches (arrows) and varicosities (arrowheads) are regulated by sensorin. Epifluorescent micrographs of the same region of the sensory neuron arbor were taken before (day 1 ) and after (day 3) respective treatments. New branches and varicosities form after Cont Ab. In contrast, no new branches and varicosities contacting L7 form after SEN Ab, whereas many new branches and varicosities form after SEN. Scale bar, $50 \mu \mathrm{m}$.

$\mu \mathrm{m} / \mathrm{branch}$ for cells treated with sensorin or $110.1 \pm 5.5 \mu \mathrm{m} /$ branch for cells treated with anti-sensorin Ab. Treatments did not significantly affect the number of new branches extending on the substrate: $5.7 \pm 0.4$ new branches per cell for Cont $\mathrm{Ab}$ compared with $5.4 \pm 0.5$ new branches per cell for SEN or $5.9 \pm 0.4$ new branches per cell for SEN Ab. The varicosities formed by sensory neurons cultured alone are not stable during this period because they are usually growth cones fasciculated and extending on existing neurites (Schacher and Proshansky, 1983; Keller and Schacher, 1990; Peter et al., 1994). Moreover, varicosities of isolated sensory neurons do not contain active zones (Glanzman et al., 1989). Thus, release of sensorin regulates selectively new axonal growth and formation of new sensory neuron varicosities that typically contain release sites for neurotransmitter (Glanzman et al., 1989; Hatada et al., 1999; Kim et al., 2003). Sensorin does not regulate axon growth or extension unrelated to synapse formation.
Sensorin release is critical for synapse stability and maintenance

After $4 \mathrm{~d}$ in culture, both efficacy and structure of sensory neuron synaptic connections with L7 are relatively stable, unless the cells are subjected to specific types of modulatory activity such as repeated exposure to 5-HT (long-term facilitation) or to the neuropeptide FMRFamide (PheMet-Arg-Phe-amide) (long-term depression) (Glanzman et al., 1990; Schacher and Montarolo, 1991). With long-term depression, the decrease in synaptic efficacy is accompanied by retraction of sensory neurites and a decrease in the number of sensory neuron varicosities (Schacher and Montarolo, 1991). We examined whether exposure to anti-sensorin $\mathrm{Ab}$ affected the stability of the sensory neuron arbor and varicosities contacting L7. After recording EPSPs and mapping the sensory neuron neurites and varicosities contacting L7 on day 5, we treated cultures with either Cont Ab or SEN Ab for $48 \mathrm{hr}$. On day 7 , synaptic efficacy and the sensory neuron arbor were reexamined (Fig. 5)

Treating stable cultures with antisensorin $\mathrm{Ab}$ results in a significant decrease in both EPSP amplitude (Fig. $5 A, B$ ) and the number of varicosities contacting L7 (Fig. 5C-E). Neurite retraction is also evident after treatment with anti-sensorin $\mathrm{Ab}$ (Fig. 5E). With Cont $\mathrm{Ab}(n=6)$, EPSP amplitudes were unchanged; they increased slightly from $25.1 \pm 1.0 \mathrm{mV}$ on day 5 to $25.9 \pm 1.0 \mathrm{mV}$ on day 7 . Treatment with SEN Ab $(n=6)$ produced a significant decline in EPSP amplitude; they decreased from $27.1 \pm 1.4$ to $18.8 \pm$ $1.3 \mathrm{mV}$ (Fig. $5 A, B$ ). The decline in EPSP amplitude with SEN Ab was correlated with a net decrease in the number of sensory neuron varicosities (Fig. $5 C, D$ ). Control treatments resulted in an insignificant net gain of $1.5 \pm 2.4 \%$ (or $0.5 \pm 0.7$ varicosities) in the number of sensory neuron varicosities contacting L7. In contrast, SEN Ab treatment resulted in a net loss of $-14.2 \pm 2.2 \%$ (or $-4.5 \pm 1.0$ varicosities) in the number of varicosities. This loss was not attributable to shrinkage of existing varicosities but to the elimination of sensory neuron neurites containing varicosities (Fig. $5 E$, inset). Thus, the constitutive release and actions of sensorin are required to maintain efficacy of sensory neuron synapses and the sensory neuron arbor and varicosities.

\section{Sensorin secretion regulates distribution of mRNA in sensory} neuron cell bodies

Sensorin release mediates target-dependent actions on the distribution of sensorin and syntaxin mRNA both during the early phases of synapse formation and when sensory neuron synapses are stable (Figs. 6, 7). The actions of sensorin are selective, because regulating exogenous sensorin levels does not affect the distribution of actin mRNA in sensory neuron cell bodies (Fig. 6). 
Day 1
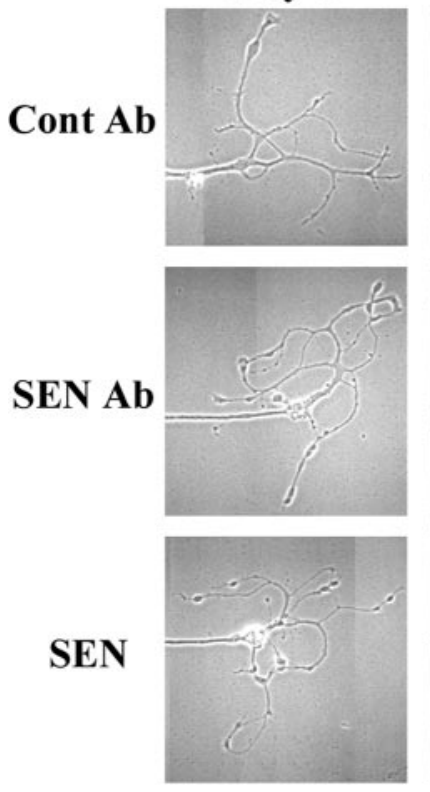

Day 2
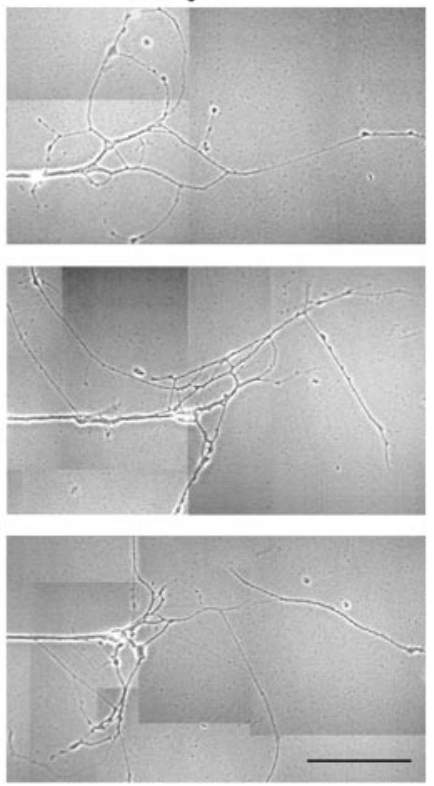

Figure 4. Sensorin fails to regulate growth of sensory neurons cultured alone. Representative examples of growth by sensory neurons after the respective treatments indicate no significant effect produced by SEN or SEN Ab. Branches extend along the substrate with some fasciculating with other branches. Nearly all structures resembling varicosities are growth cones extending on existing neurites (see Results). Scale bar, $100 \mu \mathrm{m}$.

Cocultures of SN-L7 and SN-L11 were plated in the same dishes and were exposed to the various treatments for $24 \mathrm{hr}$ starting on days 1 or 4 . After treatments, the cells were fixed and processed for in situ hybridization to detect overall expression and distribution of sensorin or actin mRNA (Fig. 6) or syntaxin mRNA (Fig. 7 ) in sensory neuron cell bodies.

Both during the early phase of synapse formation and when the synapses are stable, sensorin secretion and its actions on the cells mediate the target-dependent accumulation of sensorin mRNA at the axon hillock (Fig. 6A-D). Sensorin mRNA accumulates at the axon hillock on both days 2 and 5 when sensory neurons contact L7 but is distributed uniformly when sensory neurons contact L11 (Fig. $6 A, C$, Cont Ab, left panels; $B, D$, bar graphs). Exposure to SEN for $24 \mathrm{hr}$ beginning on day 1 resulted in the enhanced accumulation of sensorin mRNA to the axon hillock of sensory neurons contacting L7 and additional accumulation of sensorin mRNA to the axon hillock of sensory neurons contacting L11 on day 2 (Fig. $6 A, B$, middle panels). Exposure to sensorin also increased overall expression of sensorin mRNA in sensory neurons contacting L7 (42.3 \pm 3.1 intensity units compared with $32.5 \pm 2.0$ units after Cont Ab; $p<0.05)$. The accumulation at the axon hillock of sensory neurons contacting L11 that were treated with sensorin was comparable with that in sensory neurons contacting L7 under control conditions (Fig. 6A, compare bottom middle and top left panels; $B$, bar graph). This redistribution occurred without affecting overall expression of sensorin mRNA in sensory neurons contacting L11 (28.3 \pm 2.3 intensity units compared with $25.5 \pm 1.8$ intensity units after Cont $\mathrm{Ab}$ ). In contrast, treatment with anti-sensorin $\mathrm{Ab}$ resulted in the uniform distribution of sensorin mRNA in sensory neurons contacting L7 without significantly affecting overall expression (28.5 \pm 2.3 intensity units compared with $32.5 \pm 2.0$ units after Cont $\mathrm{Ab}$ ), a distribution expressed by sensory neurons contacting L11 (Fig. 6A, compare top right and bottom left panels;
A

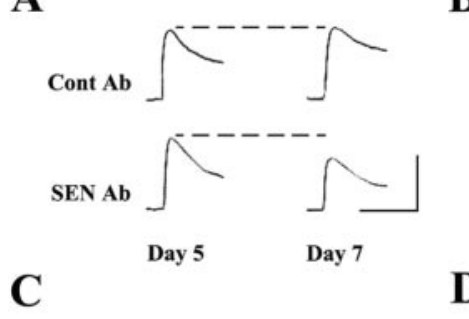

B

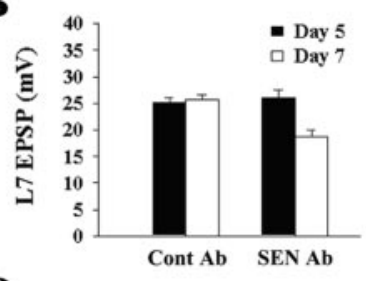

D

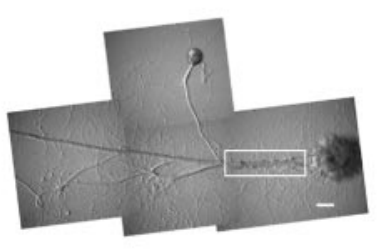

$\mathbf{E}$

Day 5
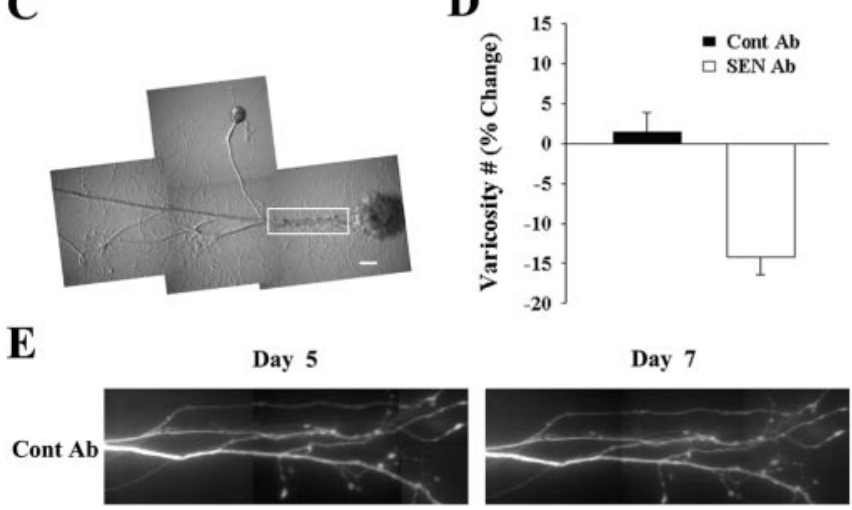

Day 7

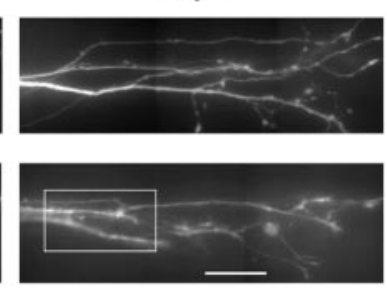

Figure 5. Sensorin is required for maintaining stable synapses. $A$, EPSPs were recorded before (day 5) and after (day 7) treatments. Synaptic efficacy remains unchanged after Cont Ab but is depressed after SEN Ab. Calibration: $20 \mathrm{mV}, 50 \mathrm{msec}$. B, Summary of the changes in EPSP amplitude with treatment. The height of each bar is the mean \pm SEM for EPSP amplitudes before (day 5) and after (day 7) treatments. ANOVA indicated an overall effect of treatment (df $=1,16 ; F=96.942 ; p<0.01)$. Individual comparisons indicated that SEN Ab reduced significantly EPSP amplitude. C, Nomarski contrast micrograph of a $7 \mathrm{~d}$ SN-L7 culture after treatment with SEN Ab. The inset indicates region of the major axons of $\mathrm{L} 7$ contacted by the portion of the sensory neuron arbor viewed in $E$. Scale bar, $50 \mu \mathrm{m}$. D, Summary of the net changes in the number of sensory neuron varicosities after treatments. The height of each bar is the mean \pm SEM for the change (percentage) in varicosity number. Treatment with SEN Ab produced a significant decline in sensory neuron varicosities $(F=23.367 ; p<0.01)$. E, Epifluorescent micrographs of portions of sensory neuron arbors contacting the major axons of $L 7$ indicate that SEN Ab causes a loss of both branches and varicosities (see inset). Treatment with Cont Ab produces no significant changes in the mature sensory neuron arbor. Scale bar, $50 \mu \mathrm{m}$.

$B)$. Uniform distribution was maintained when anti-sensorin $\mathrm{Ab}$ was applied to SN-L11 cultures (Fig. $6 A$, right panel; $B$ ). Sensory neurons in culture alone responded to the treatments as sensory neurons contacting L11 (data not shown). Thus, during the early phase of synapse formation, contact with L7, which triggers the secretion of sensorin, activates receptors on the cells to regulate sensorin mRNA distribution. On the other hand, contact with L11, which fails to induce a significant secretion of sensorin, fails to regulate the distribution of sensorin mRNA. The sensory neurons contacting L11 during this early phase, however, retain the capacity to respond to exogenous sensorin, which enhances sensorin mRNA accumulation at the axon hillock.

Actin mRNA is distributed uniformly in the cell bodies of sensory neurons contacting either L7 or L11 (Hu et al., 2002). Sensorin or anti-sensorin $\mathrm{Ab}$ applied for $24 \mathrm{hr}$ after day 1 did not affect overall expression of acting mRNA in cell bodies of sensory neurons contacting L7 (71.4 \pm 3.0 intensity units after Cont Ab, $69.7 \pm 3.3$ units after sensorin, and $68.3 \pm 2.7$ units after SEN $\mathrm{Ab})$. Regulating sensorin levels also did not affect the uniform distribution of actin mRNA in the cell bodies of sensory neurons 
A
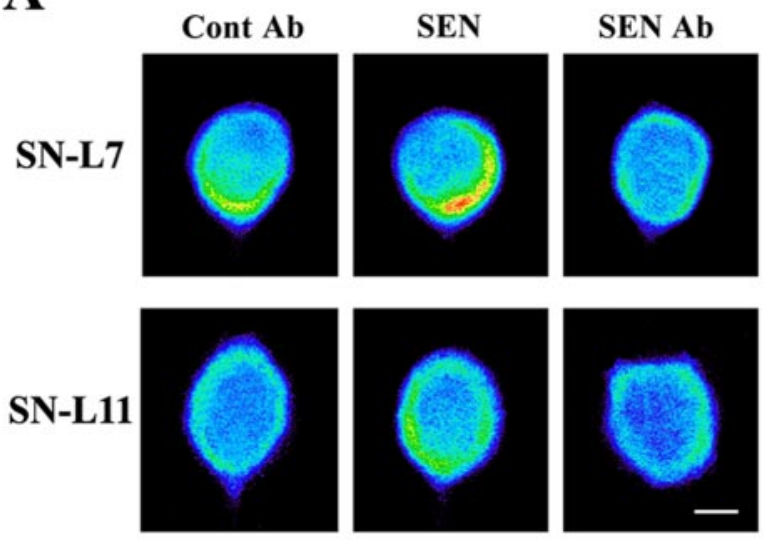

C
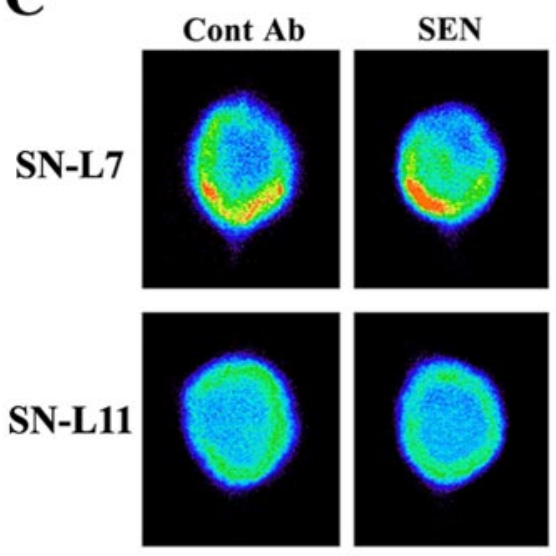

E
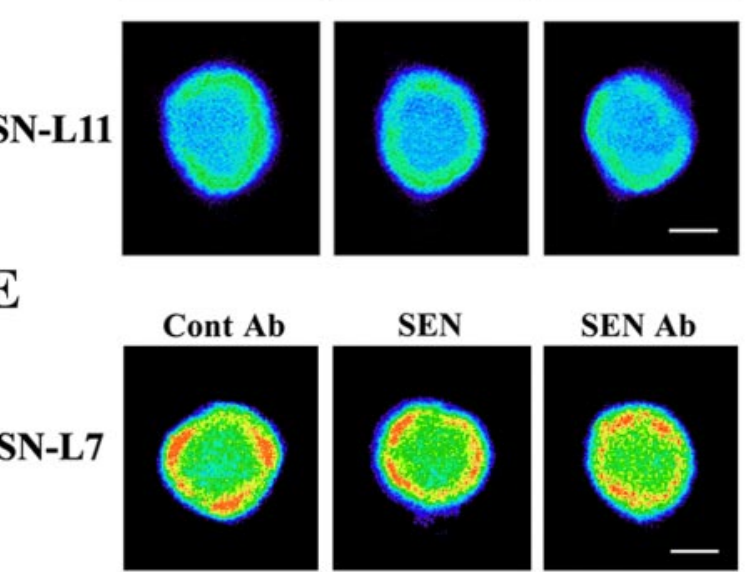
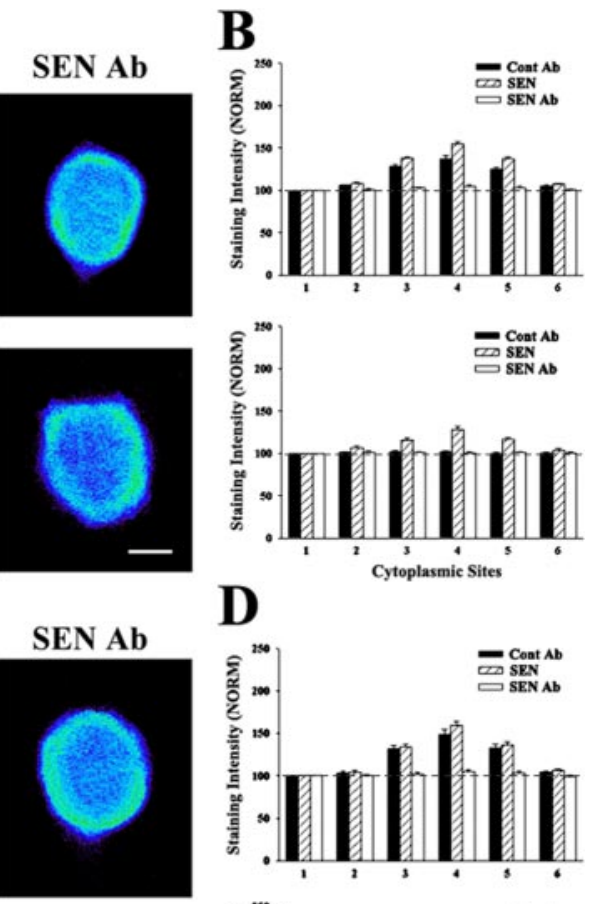

D
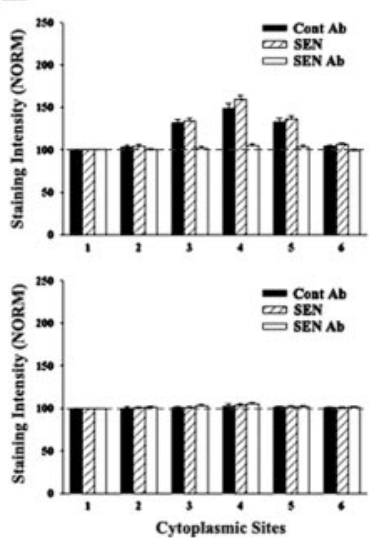

F

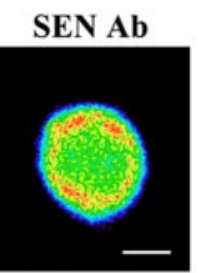

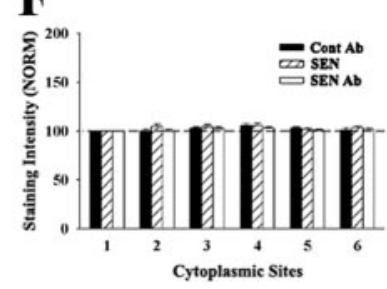

Figure 6. Sensorin mediates target-dependent regulation of sensorin mRNA distribution in sensory neuron cell bodies and does not regulate distribution of actin mRNA. $A, C, E$, Pseudocolor representations of the fluorescent in situ hybridization signal (red, high intensity; blue, low intensity) for sensorin mRNA in sensory neuron cell bodies contacting L7 (SN-L7) or L11 (SN-L11) on days $2(A)$ or 5 ( $C$ ) in culture, or actin mRNA in sensory neuron cell bodies contacting $\mathrm{L} 7$ on day $2(E)$ and $24 \mathrm{hr}$ after the indicated treatments. Sensorin is concentrated at the axon hillock region (centered at $60^{\prime}$ clock) when sensory neurons contact L7. Accumulation at the axon hillock is regulated by application of SEN or SEN Ab. SEN also regulates accumulation of sensorin mRNA at the axon hillock of sensory neurons contacting $L 11$ on day 2 but not day 5 . Overall expression of sensorin mRNA in cell bodies of sensory neurons contacting L7 is enhanced by adding sensorin on day 2 and decreased by adding anti-sensorin Ab on day 5 . Sensorin or SEN Ab do not regulate overall expression or distribution of actin mRNA. Scale bars, $25 \mu \mathrm{m} . B, D, F$, The relative distribution of sensorin mRNA in sensory neuron cell bodies contacting $\mathrm{L} 7$ (top) or $\mathrm{L} 11$ (bottom) after treatments on days $2(B)$ or $5(D)$, and actin mRNA in sensory neurons contacting $L 7$ after treatments on day $2(F)$ is summarized. At each time point, the height of each bar is the mean $\pm S E M$ for relative intensity for sensorin or actin $m R N A$ in sensory neuron cell bodies for each culture condition. ANOVA indicated an overall effect of treatment on sensorin mRNA distribution on day $2(B)(\mathrm{df}=25,180 ; F=44.961 ; p<0.001)$ and on day $5(D)(\mathrm{df}=25,150 ; F=31.798 ; p<0.001)$. There was no effect of treatment on the distribution of actin mRNA, which was distributed uniformly $(F)$. Individual comparisons for day 2 indicated that SEN or SEN Ab treatments to SN-L7 cultures had a significant effect on sensorin mRNA distribution compared with Cont Ab treatment ( $p<0.05$ or $p<0.01$, respectively). Treating SN-L11 cultures with SEN significantly altered sensorin mRNA distribution compared with SN-L11 cultures treated with Cont $\mathrm{Ab}(p<0.01)$. The distribution of sensorin mRNA in SN-L11 cultures treated with SEN was not significantly different than the distribution in SN-L7 cultures treated with Cont Ab, and the distribution in SN-L7 cultures treated with SEN Ab was not significantly different than the distribution in SN-L11 cultures treated with Cont Ab. Individual comparisons for day 5 indicated that the distribution of sensorin mRNA in SN-L7 cultures after treatment with SEN Ab was significantly different than treatment of SN-L7 cultures with Cont $\mathrm{Ab}(p<0.01)$ and was not significantly different than the distribution in SN-L11 cultures treated with Cont Ab. All treatments failed to alter the distribution of sensorin mRNA in SN-L11 cultures on day 5.

contacting L7 (Fig. 6E,F). Thus, target regulation of sensorin secretion affects the expression and distribution of selective mRNAs.

When contacts stabilize by day 5 , sensorin release continues to have the same effect on sensory neurons contacting L7; bath-applied sensorin increases slightly the accumulation of sensorin mRNA at the axon hillock, whereas anti-sensorin $\mathrm{Ab}$ produces both a significant reduction in overall expression and a more uniform distribution (Fig. 6C,D). Overall expression of sensorin mRNA is $44.8 \pm 2.3$ intensity units after peptide (SEN) compared with $40.5 \pm 2.7$ units after Cont Ab but only $25.2 \pm 2.1$ units after SEN Ab $(p<$ $0.01)$. In contrast to the changes produced during the early phase of interaction, bath application of either sensorin or antisensorin $\mathrm{Ab}$ no longer regulates the distribution of sensorin mRNA in sensory neurons contacting L11 (Fig. 6C,D). Overall expression of sensorin mRNA was also unaffected $(26.2 \pm 1.7$ intensity units after Cont Ab compared with $27.8 \pm 2.2$ units after sensorin or $25.8 \pm 2.1$ units after SEN $\mathrm{Ab})$. Thus, sensorin secretion and its actions on the cells continue to regulate expression and distribution of sensorin mRNA in sensory neurons that have formed stable synapses with L7, but prolonged interaction with L11 leads to the downregulation in overall expression of sensorin mRNA and in the capacity of sensory neurons to respond to exogenous sensorin.

Sensorin secretion also regulates the distribution of syntaxin mRNA in the cell bodies of sensory neurons and mediates the target-dependent effects on syntaxin mRNA distribution (Fig. 7). Syntaxin mRNA accumulates at the axon hillock of sensory neurons contacting L7 during the early phase of synapse formation and away from the axon hillock when synapses are stable, whereas the distribution is uniform in sensory neurons contacting L11 (Fig. $7 A, C$, Cont Ab, left panels; $B, D$, bar graphs). Bath application of sensorin during the early phase of synapse formation (Fig. 7A, middle panels) did not significantly alter overall expression but enhanced the accumulation at the axon hillock of sensory neurons contacting either L7 or L11. Overall expression for syntaxin mRNA in sensory neurons contacting $\mathrm{L} 7$ was $51.0 \pm 3.2$ intensity units after Cont $\mathrm{Ab}$ compared with $56.2 \pm 3.0$ units after sensorin and $48.0 \pm 3.3$ units after SEN Ab. Accumulation in sensory neurons contacting L11 matched that observed for sensory neu- 
rons contacting L7 in control cultures (Fig. 7A, compare bottom middle and top left panels; $B$ ). Treatment with antisensorin $\mathrm{Ab}$ had no effect on overall expression in sensory neurons contacting L11 (43.5 \pm 3.0 intensity units after SEN Ab compared with $44.5 \pm 2.7$ units after Cont $\mathrm{Ab}$ ) or the distribution of syntaxin mRNA in sensory neurons contacting L11 (it remained uniformly distributed), but it produced a major reversal in the distribution of the mRNA in sensory neurons contacting L7 without significantly affecting overall expression $(47.3 \pm 2.6$ intensity units $)$; the mRNA accumulated away from the axon hillock (Fig. $7 A$, right panel; $B$ ). The distribution matched that observed for sensory neurons that have formed stable synapses with L7 (Fig. 7C, top left panel). Sensory neurons cultured alone respond to these treatments as sensory neurons contacting L11 (data not shown). Thus, the level of sensorin secretion and its signaling appear to influence the distribution of syntaxin mRNA during the early phases of synapse formation with L7, whereas contact with L11, which fails to induce sensorin secretion, does not affect the capacity of the cells to respond to bath-applied sensorin.

As synapses mature, sensorin continues to regulate the distribution of syntaxin mRNA in sensory neurons contacting L7 but no longer regulates the distribution of the mRNA in sensory neurons contacting L11 (Fig. 7C,D). Bath application of sensorin does not alter overall expression of syntaxin mRNA in sensory neurons contacting L7 (49.2 \pm 2.3 intensity units after Cont Ab compared with $53.5 \pm 2.3$ units after sensorin and $48.3 \pm 2.6$ units after $\mathrm{SEN} \mathrm{Ab}$ ) but reverses the distribution of syntaxin mRNA in sensory neurons contacting L7 to that observed for sensory neurons contacting L7 during the early phase of synapse formation: an accumulation at the axon hillock. In contrast, no changes in distribution were detected in sensory neurons contacting L11 (Fig. $7 C, D$, middle panels). When sensory neurons contact $\mathrm{L} 11$, treatment with anti-

sensorin $\mathrm{Ab}$ had no significant effect on overall expression of syntaxin mRNA ( $41.8 \pm 2.3$ intensity units after Cont Ab compared with $40.5 \pm 1.8$ units after SEN Ab or $42.5 \pm 2.1$ units after sensorin) or on the uniform distribution of syntaxin mRNA. Anti-sensorin Ab produces only a modest effect on the distribution of the mRNA in sensory neurons contacting L7 (a small shift toward a more uniform distribution). This indicates that the change in the distribution of syntaxin mRNA with synapse stabilization is regulated by a reduction in endogenous sensorin secretion, whereas contact with L11 results in a significant reduction both in sensorin secretion and in sensorin signaling. in SN-L11 cultures on day 5.
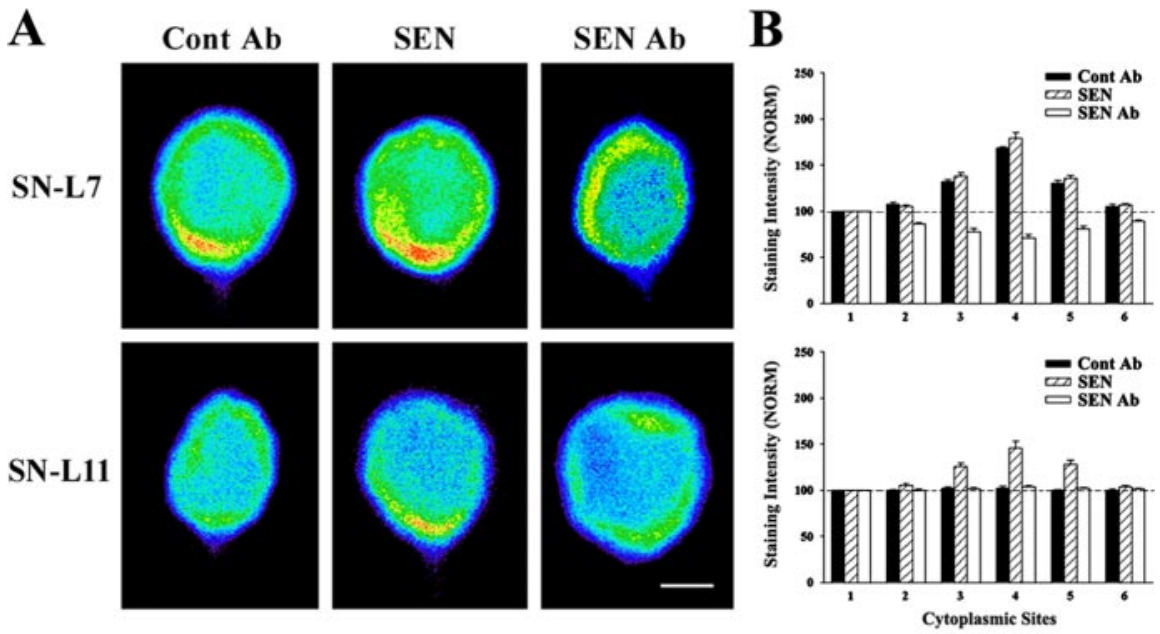

D
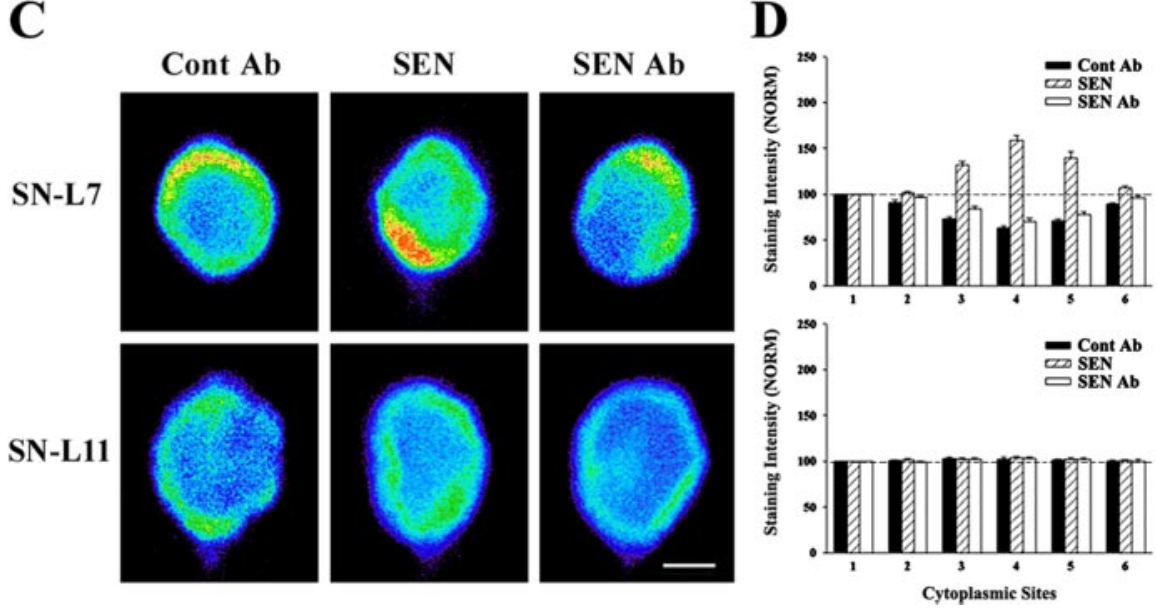

Figure 7. Sensorin mediates target-dependent regulation of syntaxin mRNA distribution in sensory neuron cell bodies. $A, C$, Pseudocolor representations of the fluorescent in situ hybridization signal (red, high intensity; blue, low intensity) for syntaxin RNA in sensory neuron cell bodies contacting L7 (SN-L7) or L11 (SN-L11) on days 2 (A) or 5 (C) in culture and $24 \mathrm{hr}$ after treatments. Syntaxin is concentrated at the axon hillock on day 2 and away from the axon hillock on day 5 when sensory neurons contact L7. The accumulation at the axon hillock is regulated by SEN or SEN Ab. On day 2, SEN also regulates accumulation of syntaxin mRNA at the axon hillock of sensory neurons contacting L11. Overall expression of syntaxin mRNA is not affected significantly by sensorin or anti-sensorin Ab. Scale bars, $25 \mu \mathrm{m}$. B, D, The relative distribution of syntaxin mRNA in sensory neuron cell bodies contacting L7 (top) or L11 (bottom) after treatments on days $2(B)$ or $5(D)$ is summarized. At each time point, the height of each bar is the mean \pm SEM for relative intensity for syntaxin mRNA at the different locations in the sensory neuron cell body for each condition. ANOVA indicated an overall effect of treatment on day $2(B)(\mathrm{df}=25,150 ; F=47.762 ; p<0.001)$ and on day $5(D)(\mathrm{df}=25,150 ; F=68.733 ; p<0.001)$. Individual comparisons for day 2 indicated that, for SN-L7 cultures, SEN Ab treatments were significantly different than treatment with Cont $\mathrm{Ab}(p<0.01)$. This treatment resulted in accumulation of syntaxin mRNA away from the cell body that is typically seen in mature SN-L7 cultures. Treating SN-L11 cultures with SEN significantly altered syntaxin mRNA distribution compared with SN-L11 cultures treated with Cont $\mathrm{Ab}(p<0.01)$. The distribution of syntaxin mRNA in SN-L11 cultures treated with SEN was not significantly different than the distribution in SN-L7 cultures treated with Cont Ab. Individual comparisons for day 5 indicated that the distribution of syntaxin mRNA in SN-L7 cultures after treatment with SEN was significantly different than treatment with Cont $\mathrm{Ab}(p<0.01)$ and was significantly different than the distribution in SN-L11 cultures treated with Cont $\mathrm{Ab}(p<0.01)$. All treatments failed to alter the distribution of syntaxin $\mathrm{mRNA}$

\section{Discussion}

Our results suggest that a retrograde signal from the target motor neuron influences both the release of sensorin and sensorinmediated responses. Initial interaction with L7 enhances the secretion of sensorin to regulate neuritic growth and varicosity formation, the increases in synaptic efficacy, and regulates the distribution of sensorin and syntaxin mRNA. Sensorin release is also critical for the maintenance of the sensory neuron arbor and varicosities, synaptic efficacy, and the distribution of syntaxin and sensorin mRNAs in sensory neuron cell bodies. In contrast, interaction with L11 fails to induce sensorin secretion and leads 
to a significant decline in sensorin-mediated changes in mRNA distribution. Because sensory neurons express receptors for sensorin (Hu et al., 2004), sensorin release and its autocrine actions play a critical role in the formation and maintenance of specific synaptic connections.

\section{Sensorin secretion regulates synapse formation and maturation}

Target-dependent release of sensorin regulates the formation of specific synapses by sensory neurons. Because sensory neurons are silent (fire action potentials only when stimulated), any secretion of sensorin occurs through constitutive or spontaneous release. One site of release is at sensory neuron varicosities, because these presynaptic structures contain high levels of sensorin and are known to have release sites (Santarelli et al., 1996; Hatada et al., 1999; Liu et al., 2003, Hu et al., 2004) (Fig. 1). Sensorin release is also important for initiating synapse formation, because sensory neurons fail to establish connections with L7 in approximately two-thirds of cultures when the cells are initially plated in the presence of anti-sensorin antibody compared with formation of synapses in $90 \%$ of control cultures $24 \mathrm{hr}$ after plating (data not shown). Thus, sensorin levels secreted into the medium affect both the initial formation and maturation of sensory neuron synapses.

Modulation of sensorin levels in the bath affects presynaptic development apparently by binding autoreceptors ( $\mathrm{Hu}$ et al., 2004). A selective receptor tyrosine kinase inhibitor blocks sensorin-mediated activation of MAPK (p42/44) and the translocation of the phosphorylated MAPK into sensory neuron nuclei (Hu et al., 2004). Although sensorin produces no detectable physiological action or MAPK activation and translocation in L7 (Hu et al., 2004), whether this postsynaptic target has receptors for sensorin is still an open question. Some other unidentified targets of sensory neurons appear to respond with hyperpolarizations to exogenous applications of sensorin A (Brunet et al., 1991). We also do not know the nature of the retrograde signal from L7 that regulates sensorin secretion. This signal must work at close range because synapse specificity and branch-specific cellular changes are observed when a single sensory neuron interacts with L7 and L11 simultaneously (Schacher et al., 1999; Hu et al., 2002). Local cell-cell communication through binding of a secreted product or through binding of surface receptors may serve to trigger this local response. We also do not know how the retrograde signal from L7 regulates sensorin secretion. Perhaps the target signal regulates second-messenger cascades within sensory neuron varicosities to facilitate sensorin secretion (Ghirardi et al., 2004; Hu et al., 2004).

Sensorin influences synaptic growth: growth of sensory neurites and formation of new varicosities contacting the major processes of L7. Axonal growth, varicosity formation, and increases in synaptic efficacy are all blocked when the actions of sensorin are blocked by exogenous anti-sensorin Ab. Previous studies (Glanzman et al., 1989, 1990; Bailey et al., 1992; Bank and Schacher, 1992; Zhu et al., 1997; Casadio et al., 1999; Hatada et al., 1999; Kim et al., 2003) indicate that the formation of varicosities on the major processes of L7 is a consequence of neuritic growth, includes the formation of new release sites, and increases in synaptic efficacy. However, modulation of sensorin levels has little influence on axon extension by sensory neurons growing alone. Thus, a retrograde signal from the target also "primes" the sensory neurons to make them responsive to sensorin levels both during the early phase of synapse formation and as synapses mature and become stable. The potential activation of a receptor tyrosine kinase by sensorin ( $\mathrm{Hu}$ et al., 2004) may set in motion multiple signal transduction pathways that are characteristic of trk receptors that bind neurotrophins (for review, see Huang and Reichardt, 2001; Segal, 2003) to regulate the formation of new presynaptic varicosities at distal locations along with the changes in the distribution of mRNAs in sensory neuron cell bodies (see below).

Constitutive release of sensorin and activation of its signaling pathway also play critical roles in maintaining stable sensory neuron synapses. Reducing sensorin levels with extracellular antisensorin $\mathrm{Ab}$ destabilizes the presynaptic arbor leading to neurite retraction and loss of varicosities, and a decrease in synaptic efficacy. The maintenance of the signaling pathway of sensorin in the sensory neuron is also dependent on a retrograde signal from the target, because prolonged interaction with L11 reduces the capacity for sensory neurons to respond to applied sensorin (see below). The maintenance of the signaling pathway of sensorin in sensory neurons is also essential for the cells to express long-term synaptic plasticity. Long-term facilitation produced by 5-HT requires both increased sensorin secretion and activation of the sensorin signaling pathway ( $\mathrm{Hu}$ et al., 2004). Thus, sensorin, like neurotrophins such as BDNF, can have multiple functions, including producing neurotransmitter-like responses in some follower cells and acting as a neuromodulator in producing longterm facilitation when it interacts with autoreceptors whose signaling pathway is also activated by the stimuli required to produce long-term facilitation ( $\mathrm{Hu}$ et al., 2004). Neurotrophins and their receptors are one group of factors that contribute not only to proliferation, survival, and early differentiation of neurons but also to the formation and maintenance of peripheral synapses (Schafer et al., 1983; Gonzalez et al., 1999; Wells et al., 1999; Lockhart et al., 2000; Belluardo et al., 2001; Chen et al., 2002) and the formation, fine-tuning, maintenance, and longterm modulation of central synapses (Cabelli et al., 1995, 1997; Kang and Schuman, 1995; McAllister et al., 1997; Martinez et al., 1998; Cohen-Cory, 2002; Vicario-Abejon et al., 2002).

\section{Sensorin mediates target-dependent regulation of mRNA distribution in sensory neurons}

The distribution of mRNA within cells plays an important role in the local expression of proteins (Palacios and St. Johnston, 2001). In neurons, the accumulation of specific mRNAs at or near growth cones or developing synapses and their local translation can affect the trajectory of growth, synapse formation, or plasticity (Casadio et al., 1999; Campbell and Holt, 2001; Steward and Schuman, 2001; Schacher and Wu, 2002). Sensory neurons accumulate sensorin and syntaxin mRNAs at specific locations in a target-dependent manner (Hu et al., 2002, 2003). Accumulation at these sites affects transport to distal sites of both translated protein and mRNA (Hu et al., 2002, 2003). Our results indicate that target-dependent release of sensorin regulates distribution of specific mRNAs in sensory neuron cell bodies.

The accumulation of sensorin and syntaxin mRNA at the axon hillock during the early phase of synapse formation is regulated by the target-dependent release of sensorin and its capacity to respond to sensorin. In the presence of L11, accumulation of the mRNAs at the axon hillock is produced only after artificially increasing sensorin levels in the bath. As synapses mature, sensorin secretion and signaling appear to be reduced compared with the early phase of synapse formation. These reductions lead to the accumulation of syntaxin mRNA away from the axon hillock. The mRNA accumulation away from the axon hillock can be induced during the early phase of synapse formation when anti- 
sensorin antibodies block the actions of secreted sensorin. Additional support for the decline in sensorin release and its actions as synapses mature is that adding exogenous sensorin to mature cultures results in the reaccumulation of syntaxin mRNA to the axon hillock, as detected during the early phase of synapse formation when sensorin secretion is high. Interestingly, the reduction of sensorin release with maturation does not interfere with the continued accumulation of sensorin mRNA at the axon hillock. However, when sensorin levels in the bath are reduced further by the application of anti-sensorin antibody, the distribution of sensorin mRNA becomes uniform, behavior detected when sensory neurons interact with L11. Even this reduced level of sensorin release and responsiveness with maturation is target dependent. On day 5, sensory neurons contacting L11 fail to respond to different sensorin levels in the bath.

The effects of the target on the sensorin signaling pathway may explain the target dependence of responses by sensory neurons to neurotransmitters that produce long-term plasticity. Sensorin secretion and its signaling pathway are critical for the expression of long-term facilitation produced by 5-HT (Hu et al., 2004). Sensory neurons in culture alone or contacting L11 fail to express growth-associated changes after exposures to 5-HT that produce long-term synaptic facilitation (Glanzman et al., 1990). Sensory neurons contacting L11 also fail to respond to neuromodulatorinduced changes in the expression of specific mRNA splice variants of cell adhesion molecules (Schacher et al., 2000) or in the distribution of sensorin mRNA (Sun et al., 2001). Our results therefore suggest a central role for secretion of this neuropeptide in specific synapse formation, maturation, maintenance, and plasticity. They also suggest that different components of the complex signaling pathways initiated by sensorin binding an autoreceptor may have specialized roles in mediating the multiple actions required for making, maintaining, and modulating specific synapses.

\section{References}

Bailey CH, Chen M, Montarolo PG, Kandel ER, Schacher S (1992) Inhibitors of protein and RNA synthesis block structural and functional changes accompanying long-term synaptic facilitation and inhibition in Aplysia sensory neurons. Neuron 9:749-758.

Bank M, Schacher S (1992) Segregation of presynaptic inputs on an identified target neuron in vitro: structural remodeling visualized over time. J Neurosci 12:2960-2972.

Belluardo N, Westerblad H, Mudo G, Casabona A, Bruton J, Caniglia G, Pastoris O, Grassi F, Ibanez CF (2001) Neuromuscular junction disassembly and muscle fatigue in mice lacking neurotrophin-4. Mol Cell Neurosci 18:56-67.

Benson DL, Colman DR, Huntley GW (2001) Molecules, maps and synapse specificity. Nat Rev Neurosci 2:899-909.

Brunet JF, Shapiro E, Foster SA, Kandel ER, Iino Y (1991) Identification of a peptide specific for Aplysia sensory neurons by PCR-based differential screening. Science 252:856-859.

Cabelli RJ, Hohn A, Shatz CJ (1995) Inhibition of ocular dominance column formation by infusion of NT-4/5 or BDNF. Science 267:1662-1666.

Cabelli RJ, Shelton DL, Segal RA, Shatz CJ (1997) Blockade of endogenous ligands of trkB inhibits formation of ocular dominance columns. Neuron 19:63-76.

Camardo J, Proshansky E, Schacher S (1983) Identified Aplysia neurons form specific chemical synapses in culture. J Neurosci 3:2614-2620.

Campbell DS, Holt CE (2001) Chemotropic responses of retinal growth cones mediated by rapid local protein synthesis and degradation. Neuron 32:1013-1026.

Casadio A, Martin KC, Giustetto M, Zhu H, Chen M, Bartsch D, Bailey CH, Kandel ER (1999) A transient, neuron-wide form of CREB-mediated long-term facilitation can be stabilized at specific synapses by local protein synthesis. Cell 99:221-237.

Chen HH, Tourtellotte WG, Frank E (2002) Muscle spindle-derived neuro- trophin 3 regulates synaptic connectivity between muscle sensory and motor neurons. J Neurosci 22:3512-3519.

Cohen-Cory S (2002) The developing synapse: construction and modulation of synaptic structures and circuits. Science 298:770-776.

Davis GW, Bezprozvanny I (2001) Maintaining the stability of neural function: a homeostatic hypothesis. Annu Rev Physiol 63:847-869.

Ghirardi M, Benfenati F, Giovedi S, Fiumara F, Milanese C, Montarolo PG (2004) Inhibition of neurotransmitter release by a nonphysiological target requires protein synthesis and involves cAMP-dependent and mitogen-activated protein kinases. J Neurosci 24:5054-5062.

Glanzman DL, Kandel ER, Schacher S (1989) Identified target motor neuron regulates neurite outgrowth and synapse formation of Aplysia sensory neurons in vitro. Neuron 3:441-450.

Glanzman DL, Kandel ER, Schacher S (1990) Target-dependent structural changes accompanying long-term synaptic facilitation in Aplysia neurons. Science 249:799-802.

Gonzalez M, Ruggiero FP, Chang Q, Shi YJ, Rich MM, Kraner S, BaliceGordon RJ (1999) Disruption of Trkb-mediated signaling induces disassembly of postsynaptic receptor clusters at neuromuscular junctions. Neuron 24:567-583.

Hatada Y, Wu F, Silverman R, Schacher S, Goldberg DJ (1999) En passant synaptic varicosities form directly from growth cones by transient cessation of growth cone advance but not of actin-based motility. J Neurobiol 41:242-251.

Hawver DB, Schacher S (1993) Selective fasciculation as a mechanism for the formation of specific chemical connections between Aplysia neurons in vitro. J Neurobiol 24:368-383.

Hu JY, Meng X, Schacher S (2002) Target interaction regulates distribution and stability of specific mRNAs. J Neurosci 22:2669-2678.

Hu JY, Meng X, Schacher S (2003) Redistribution of syntaxin mRNA in neuronal cell bodies regulates protein expression and transport during synapse formation and long-term synaptic plasticity. J Neurosci 23:1804-1815.

Hu JY, Glickman L, Wu F, Schacher S (2004) Serotonin regulates the secretion and autocrine action of a neuropeptide to activate MAPK required for long-term facilitation in Aplysia. Neuron 43:373-385.

Huang EJ, Reichardt LF (2001) Neurotrophins: roles in neuronal development and function. Annu Rev Neurosci 24:677-736.

Huber AB, Kolodkin AL, Ginty DD, Cloutier JF (2003) Signaling at the growth cone: ligand-receptor complexes and the control of axon growth and guidance. Annu Rev Neurosci 26:509-563.

Kang H, Schuman EM (1995) Long-lasting neurotrophin-induced enhancement of synaptic transmission in the adult hippocampus. Science 267:1658-1662.

Katz LC, Shatz CJ (1996) Synaptic activity and the construction of cortical circuits. Science 274:1133-1138.

Keller F, Schacher S (1990) Neuron-specific membrane glycoproteins promoting neurite fasciculation in Aplysia californica. J Cell Biol 111:2637-2650

Kim JH, Udo H, Li HL, Youn TY, Chen M, Kandel ER, Bailey CH (2003) Presynaptic activation of silent synapses and growth of new synapses contribute to intermediate and long-term facilitation in Aplysia. Neuron 40:151-165.

Liu J, Schwartz JH (2003) The cytoplasmic polyadenylation element binding protein and polyadenylation of messenger RNA in Aplysia neurons. Brain Res 959:68-76.

Liu K, Hu JY, Wang D, Schacher S (2003) Protein synthesis at synapse versus cell body: enhanced but transient expression of long-term facilitation at isolated synapses. J Neurobiol 56:275-286.

Lockhart ST, Mead JN, Pisano JM, Slonimsky JD, Birren SJ (2000) Nerve growth factor collaborates with myocyte-derived factors to promote development of presynaptic sites in cultured sympathetic neurons. J Neurobiol 42:460-476.

Martinez A, Alcantara S, Borrell V, Del Rio JA, Blasi J, Otal R, Campos N, Boronat A, Barbacid M, Silos-Santiago I, Soriano E (1998) TrkB and TrkC signaling are required for maturation and synaptogenesis of hippocampal connections. J Neurosci 18:7336-7350.

McAllister AK, Katz LC, Lo DC (1997) Opposing roles for endogenous BDNF and NT-3 in regulating cortical dendritic growth. Neuron 18:767-778.

Palacios IM, St. Johnston D (2001) Getting the message across: the intracel- 
lular localization of mRNAs in higher eukaryotes. Annu Rev Cell Dev Biol 17:569-614.

Peter N, Aronoff B, Wu F, Schacher S (1994) Decrease in growth coneneurite fasciculation by sensory or motor cells in vitro accompanies down regulation of Aplysia cell adhesion molecules by neurotransmitters. J Neurosci 14:1413-1421.

Rayport SG, Schacher S (1986) Synaptic plasticity in vitro: cell culture of identified Aplysia neurons mediating short-term habituation and sensitization. J Neurosci 6:759-763.

Santarelli L, Montarolo PG, Schacher S (1996) Neuropeptide localization in varicosities of Aplysia sensory neurons is regulated by target and neuromodulators evoking long-term synaptic plasticity. J Neurobiol 31:297-308.

Schacher S, Montarolo PG (1991) Target-dependent structural changes in sensory neurons of Aplysia accompany long-term heterosynaptic inhibition. Neuron 6:679-690.

Schacher S, Proshansky E (1983) Neurite regeneration by Aplysia neurons in dissociated cell culture: modulation by Aplysia hemolymph and the presence of the initial axonal segment. J Neurosci 3:2403-2413.

Schacher S, Wu F (2002) Synapse formation in the absence of cell bodies requires protein synthesis. J Neurosci 22:1831-1839.

Schacher S, Wu F, Panyko JD, Sun ZY, Wang D (1999) Expression and branch-specific export of mRNA are regulated by synapse formation and interaction with specific postsynaptic targets. J Neurosci 19:6338-6347.

Schacher S, Wu F, Sun ZY, Wang D (2000) Cell-specific changes in expression of mRNAs encoding splice variants of Aplysia cell adhesion molecule accompany long-term synaptic plasticity. J Neurobiol 45:152-161.

Schafer T, Schwab ME, Thoenen H (1983) Increased formation of pregan- glionic synapses and axons due to a retrograde trans-synaptic action of nerve growth factor in the rat sympathetic nervous system. J Neurosci 3:1501-1510

Scheiffele P (2003) Cell-cell signaling during synapse formation in the CNS. Annu Rev Neurosci 26:485-508.

Segal RA (2003) Selectivity in neurotrophin signaling: theme and variations. Annu Rev Neurosci 26:299-330.

Steward O, Schuman EM (2001) Protein synthesis at synaptic sites on dendrites. Annu Rev Neurosci 24:299-325.

Sun ZY, Wu F, Schacher S (2001) Rapid bidirectional modulation of mRNA expression and export accompany long-term facilitation and depression of Aplysia synapses. J Neurobiol 46:41-47.

Tessier-Lavigne M, Goodman CS (1996) The molecular biology of axon guidance. Science 274:1123-1133.

Vicario-Abejon C, Owens D, McKay R, Segal M (2002) Role of neurotrophins in central synapse formation and stabilization. Nat Rev Neurosci 3:965-974.

Wells DG, McKechnie BA, Kelkar S, Fallon JR (1999) Neurotrophins regulate agrin-induced postsynaptic differentiation. Proc Natl Acad Sci USA 96:1112-1117.

Zhu H, Wu F, Schacher S (1994) Aplysia cell adhesion molecules and serotonin regulate sensory cell-motor cell interactions during early stages of synapse formation in vitro. J Neurosci 14:6886-6900.

Zhu H, Wu F, Schacher S (1997) Site-specific and sensory neurondependent increases in postsynaptic glutamate sensitivity accompany serotonin-induced long-term facilitation at Aplysia sensorimotor synapses. J Neurosci 17:4976-4986. 